\title{
High Altitude Balloon Payload Design for Atmospheric Observations
}

\author{
Rama Okta Wiyagi*1 ${ }^{*}$ Danardono $^{2}$, Try Ahmad Agus ${ }^{3}$ \\ ${ }^{1,2,3}$ Departement of Electrical Engineering, Faculty of Engineering \\ Universitas Muhammadiyah Yogyakarta \\ Kampus Terpadu UMY, Jl. Lingkar Selatan, Kasihan Bantul, Yogyakarta 55183, Indonesia \\ *Corresponding author, e -mail: ramaoktawiyagi@umy.ac.id
}

\begin{abstract}
In 2016, Microcontroller Research Group at Dept. of Electrical Engineering Universitas Muhammadiyah Yogykarta has designed and developed a payload for High Altitude Balloon. This payload has function measuring atmospheric parameter vertically and sending the data to ground station on earth using telemetry. The parameters measured are air pressure, temperature and relative humidity. Besides sending these parameters, payload also have mission monitoring real positions of payload using GPS, real time video transmission, regulary capturing and sending image from payload. This payload is tested on the annual Atmosphere Balloon Payload Competition (KOMBAT) 2016. This paper will describe the design payload, payload software algorithms and the results that have been obtained.Copyright (C) 2017 Universitas Muhammadiyah Yogyakarta- All rights reserved.
\end{abstract}

Keywords: high altitude balloon payload, atmospheric parameter, air pressure, temperature, relative humidity, telemetry.

\section{Introduction}

The atmosphere is a layer of gas mixture that wraps around the surface of the earth and serves as a protector of the life of living things on earth. The weather conditions on this earth are fully influenced by the atmosphere because the atmosphere is able to withstand the heat of the earth coming out and entering the earth.Observation is needed to get the actual condition of atmosphere.

The purpose of observation and recording is to obtain complete and appropriate data on the condition of a particular area. The updated weather information of a region is important. One of the technological advances used to observe and record the atmospheric conditions of the Earth's surface is the atmospheric balloon. This balloon has electronic payload to measure the profile of temperature, humidity, and also the air pressure on the surface of the earth. In addition, the physical surface capturing of the earth based on altitude, latitude, and longitude is also necessary to determine the condition of atmospheric profiles above the earth's surface.

Annualy Indonesian National Institute of Aeronautics and Space (LAPAN) with Ministry of Research, Technology and Higher Education organize an event called Atmosphere Balloon Payload Competitions (KOMBAT). In this competition, selected participants can test the payload in real atmosphere environment using high altitude balloon provided by LAPAN. In 2016, Microcontroller Research Group Team at Dept. of Electrical Engineering Universitas Muhammadiyah Yogykarta (UMY) has been selected and participated in this event.

In this paper will describe the design payload include hardware design such as sensor unit, data processing section, power supply unit, telemetry radio and video transmission section. Also generally describe payload application algorithms and the results that have been obtained during competition. 


\section{Payload Mission}

Payload will conduct the following mission.

- Atmospheric parameter measurement consist of air pressure, temperature and relative humidity.

- Sea surface and costal area monitoring using camera.

- Sending atmospheric parameter data, video and image captured by payload wirelessly to ground station.

\section{System Design}

Payload is designed and developed by following the KOMBAT 2016 rule. Generally payload divided into subsystem such as sensor, data processing section, power supply unit (PSU), telemetry radio and video transmission section. In the sensor section, the components of the electronic circuit will detect the parameters according to the function of each sensor. After the measurement parameter values obtained then processed on the data processing section. Microcontroller and a single board computer is used to process data in data processing section. Microcontroller will process the data from the entire sensor, while the single board computer will process the image data captured from camera and combine it with sensor data. The results of combining sensor and image data are sent to Ground Station (GS) using $433 \mathrm{MHz}$ telemetry radio transmitter on the payload. Payload has a video transmitting section in charge of sending realtime video from payload to GS using transmitter at 5.8GHz. Figure 1 shows the block diagram of payload system.

\section{III.1. Sensor Unit}

Here are the sensors used in the design of the payload:

- HTU21D

- MS5611-01BA03

- Ublox NEO-M8N GPS

HTU21D is a high performance digital relative humidity sensor, low cost and easy to use. This sensor is ideal for environmental sensing, data logging and perfect for weather stations. In addition to relative humidity, these sensors are capable of performing temperature measurements. Each sensor individually has been calibrated and tested by the manufacturer. The output data has been linearized in digital form and can be read directly by microcontroller. The data protocol uses $\mathrm{I}^{2} \mathrm{C}$ which requires only two data line [1]. Considering specification of sensor the operating range of humidity readings and temperature, this sensors is a suitable to be applied to the payload. Here are the HTU21D sensor specifications.

TABLE I

HTU21D SPECIFICATION

\begin{tabular}{lll}
\hline Ratings & Value & Unit \\
\hline Supply Voltage (Max) & 3.6 & Volt \\
\hline Humidity operation range & 0 to 100 & $\% \mathrm{RH}$ \\
\hline Temperature Range & -40 to +125 & ${ }^{\circ} \mathrm{C}$ \\
\hline Current Consumtion (Typ) & 450 & $\mu \mathrm{A}$ \\
\hline
\end{tabular}

MS5611-01BA03 is high resolution barometric preassure sensor. This sensor optimized for altimeters and variometer. High resolution specification achieved using 24 bit $\Delta \Sigma$ onboard

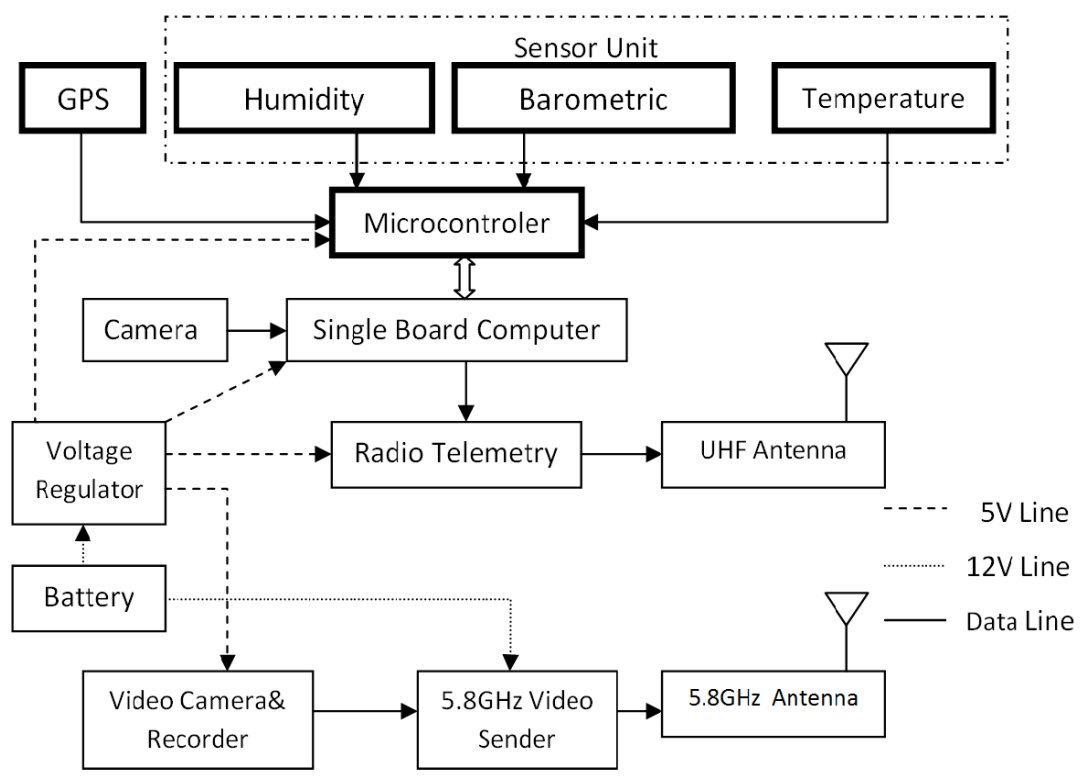

Fig. 1. Payload System Block Diagram 
ADC with internal factory calibrated coefficiens. Sensor provide a precise 24 bit pressure and temperature value [2]. This value can be accesed using SPI and $\mathrm{I}^{2} \mathrm{C}$ interface. Because both sensor (HTU21D and MS5611-01BA03) can measure temperature so there is no need special temperature sensor on payload. Table 2 shows sensor specification. Figure 2 shows humidity and pressure sensor on this sensor unit.

TABLE 2

MS5611-01BA03 SPECIFICATION

\begin{tabular}{lll}
\hline Ratings & Value & Unit \\
\hline Supply Voltage (Max) & 4 & Volt \\
\hline Pressure range & 10 to 1200 & $\mathrm{mbar}$ \\
\hline Pressure Resolution(up to) & 0.012 & $\mathrm{mbar}$ \\
\hline Temperature Range & -40 to +85 & ${ }^{\circ} \mathrm{C}$ \\
\hline Temperature Resolution & $<0.01$ & ${ }^{\circ} \mathrm{C}$ \\
\hline Current Consumtion (Typ) & 1.4 & $\mathrm{~mA}$ \\
\hline
\end{tabular}

Ublox NEO-M8N GPS module is used in payload to provide payload actual position data. This GPS can receive up to 3 GNSS (GPS, Galileo, GLONASS, also BeiDou) 72-channel with position accuracy up to 2.0 meter CEP. Operating voltage $2.7 \mathrm{~V}$ to $3.6 \mathrm{~V}$ and current consumtion $21 \mathrm{~mA} @$ $3 \mathrm{~V}$ (continuous mode) [3]. Based on specification and altitude operation up to $50,000 \mathrm{~m}$, this GPS module very suitable to use in payload.

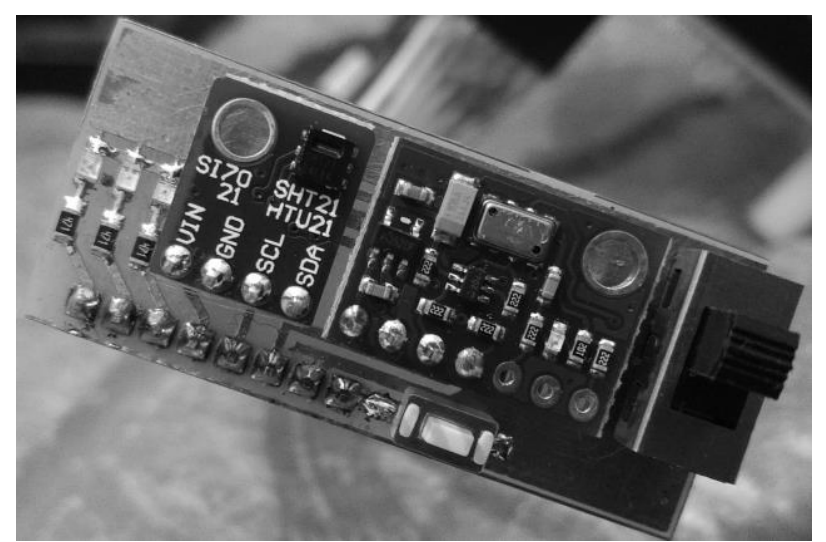

Fig. 2. HTU21D and MS5611-01BA03 in Sensor

\section{III.2. Data Processing Section}

The payload uses a ATMega328 microcontroller to process all sensor data and a Single Board Computer (SBC) to process image data. Single Board Computer used on this payload is Raspberry $\mathrm{Pi}$ At. This SBC powered by $700 \mathrm{MHz}$ ARM processesor and Linux Operating System. With high specification SBC all processing data such as image processing both capturing, conversion, and merging with data sensor can be done quickly. Raspberry Pi Cam is used to capture image. Raspberry Pi Cam is a camera specially designed for Raspberry Pi family SBC. This camera has OmniVision Sensor 5647 with resolution up to $5 \mathrm{MP}$ fixed focus lens. Camera size is small only 25 x $24 \mathrm{~mm}$ as well as lightweight, very appropriately used on payload. Figure 3 shows SBC connected with power supply unit, sensor board and image camera.

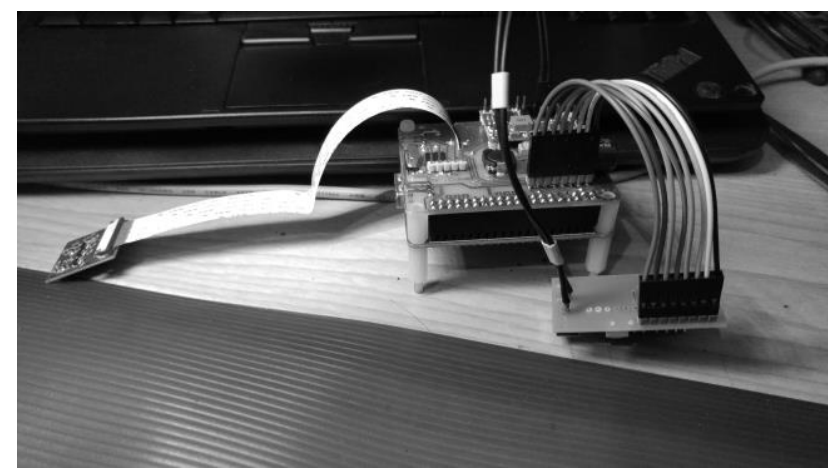

Fig. 3. SBC,PSU, Sensor Board, and Rasp Pi Cam

\section{III.3. Power Supply Unit}

The main power on this payload is 3-cell series Lithium Polymer battery. This battery have specification 11.1 Volt and capacity up to $1000 \mathrm{mAh}$ with small dimension, lightweight, and high density power. From battery,the voltage is regulated using MP1584 DC-DC converter to provide power for sensor, data processing unit, and telemetry radio.

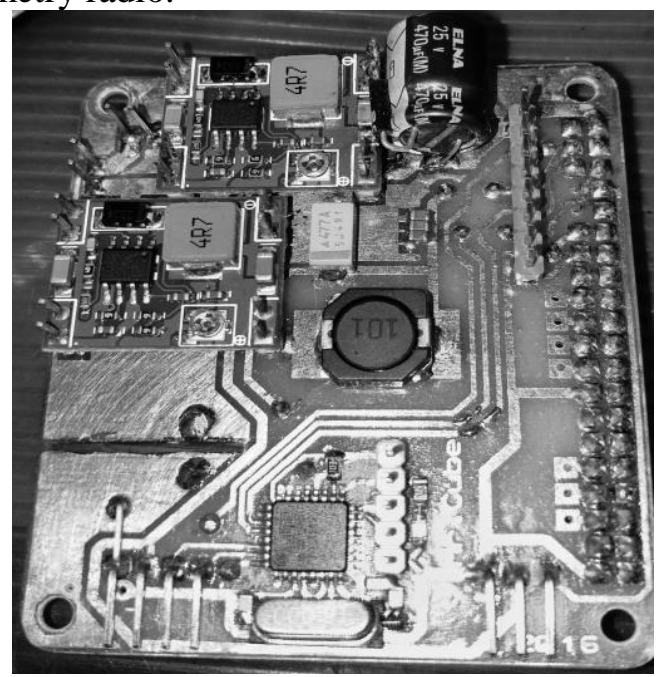

Fig. 4. Power Supply Unit and Microcontroller Data Sensor Processor 


\section{III.4. Telemetry Radio}

Wireless communication between payload and GS is provide using telemetry radio based on HMTRP. This telemetry radio have transmission power $20 \mathrm{dBm}$ or $100 \mathrm{~mW}$ output power and $-117 \mathrm{dBm}$ receive sensitivity. Operating frequency used in payload is $433 \mathrm{MHz}$. With build in error correction code can correct up to $25 \%$ of data error. This telemetry radio very reliable and give nice performance. With tuned halfwave antenna at payload and high gain 10 element $\mathrm{x} 2$ array yagi in GS can reach $30 \mathrm{~km}$ (LOS condition).

\section{III.5. Video Transmission Section}

This section handle realtime video transmission from payload to GS. Camera for video capturing is different from image capturing. Video camera using small CMOS based analog camera. This camera resolution $320 \times 240$ pixel and feed to $5.8 \mathrm{GHz}$ $600 \mathrm{~mW}$ video TX with Clover Leaf RHCP antenna. All componens in this section direcly powered from battery. Figure 5 shows this section.

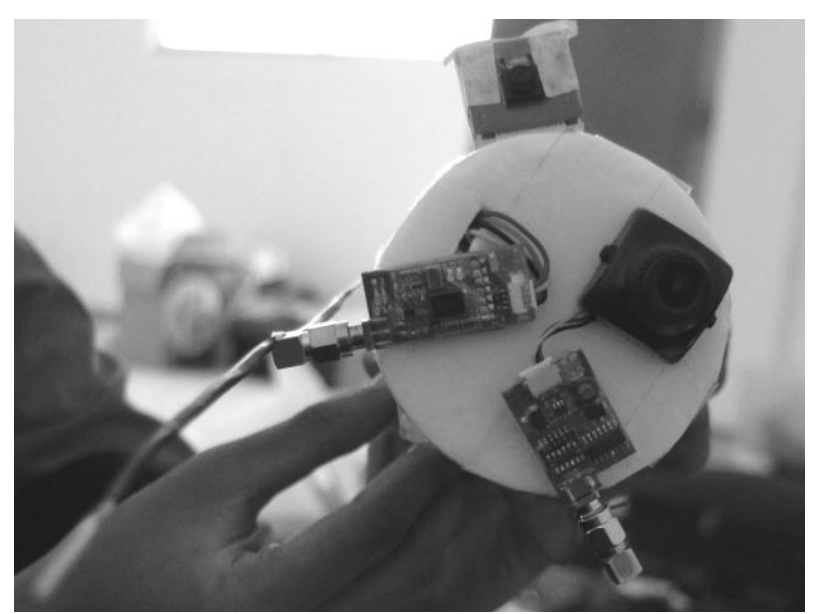

Fig. 5. Video Transmission Section and Telemetry Radio

\section{III.6. Payload Application Algorithm}

Generally designed payload application very straight forward. In microcontroller part regularly request data from each humidity, preassure sensor and GPS. Microcontroller processing data to get appropriate value. Raspberry Pi A+ as SBC collect data from microcontroller and combine with image data capture by Raspberry Pi Camera. After this step, this data feed to telemetry radio. Figure 6 shows flowchart payload application algorithm.

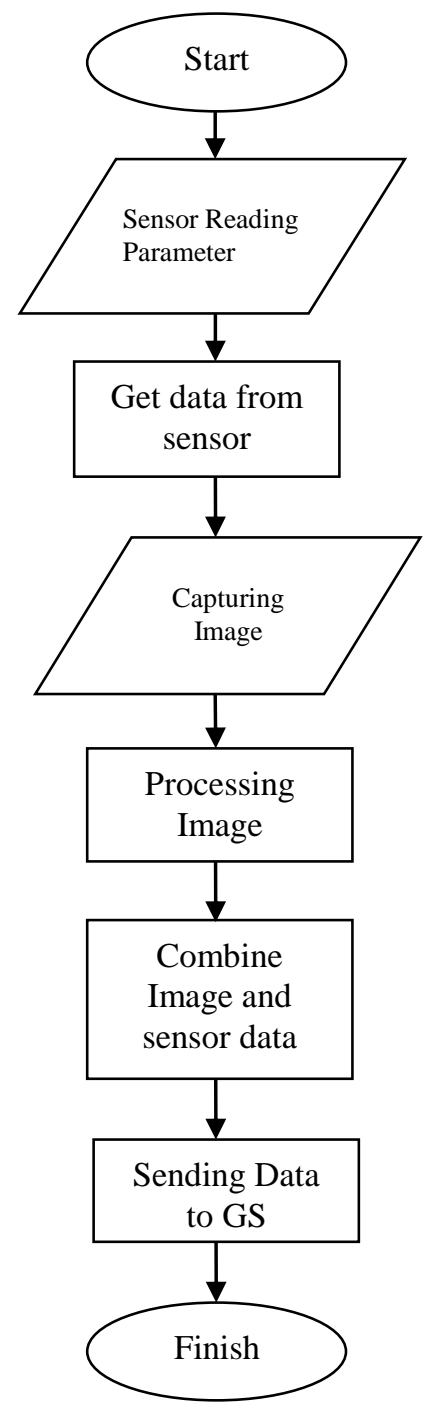

Fig. 6. Payload Application Algorithm Flowchart

\section{Result}

Payload prototype casing is using polyfoam. Polyfoam material is choose because has good thermal isolation, lightweight, easy to work, and give enough protection to all component inside payload. Finished payload shown in Figure 7.

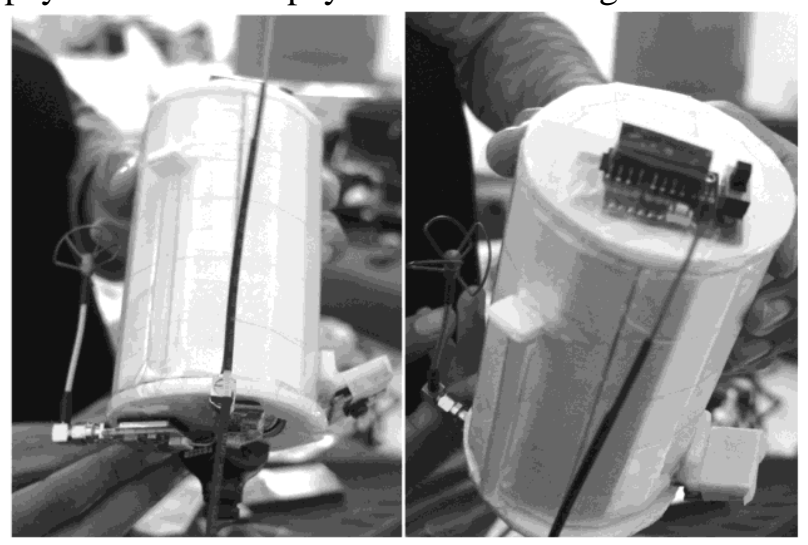

Fig. 7. The Payload 
During competition high altitude balloon airs for almost 2 hours with altitude limit $10 \mathrm{~km}$ and got 551 series data that can be read. Result are shown on graph figure 8 until figure 11.

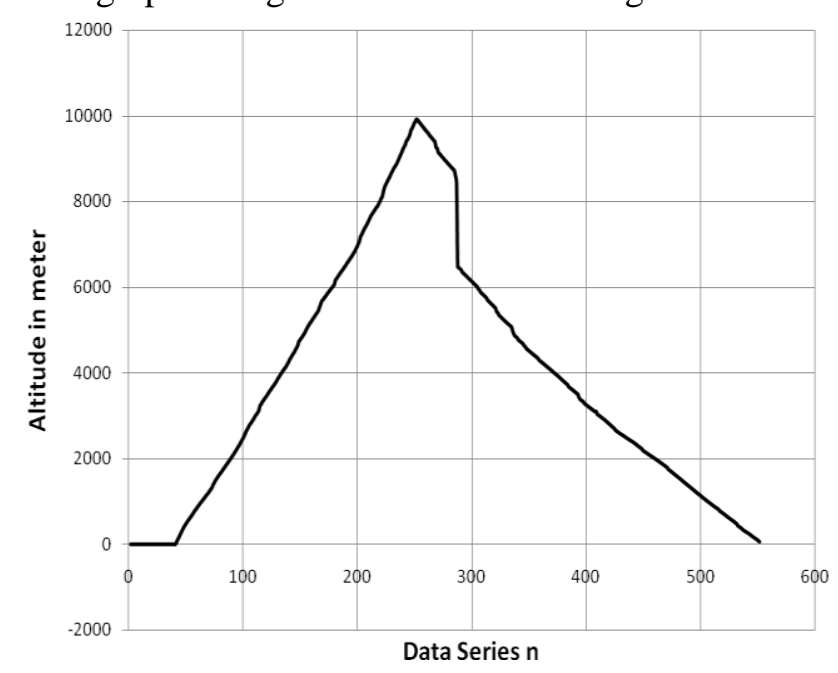

Fig. 8. Altitude Record During Mission

Altitude record during mission shown in figure 8. Maximum altitude reached is 9915 meter above sea level. During payload descending graph seen falls for a moment. This happened because GS cannot receive data from payload for about 10 minutes. Figure 9 shows relation between altitude and air pressure.

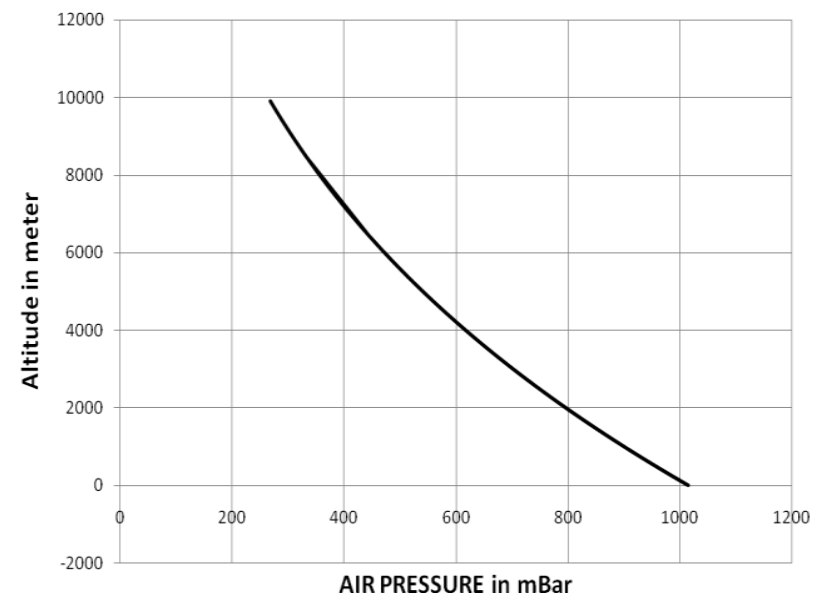

Fig. 9. Altitude vs Air Pressure

At beginning mission air pressure recorded at 1013 mBar. At maximum balloon altitude air pressure drop until 267 mBar. Figure 10 shows recorded temperature during payload ascending and figure 11 shows temperature change during payload descending. Lowest temperature reach $-29{ }^{\circ} \mathrm{C}$ at maximum balloon altitude or 9915 meter. $0{ }^{\circ} \mathrm{C}$ reached at about 500 meter altitude. Temperature at earth surface recorded $25^{\circ} \mathrm{C}$.

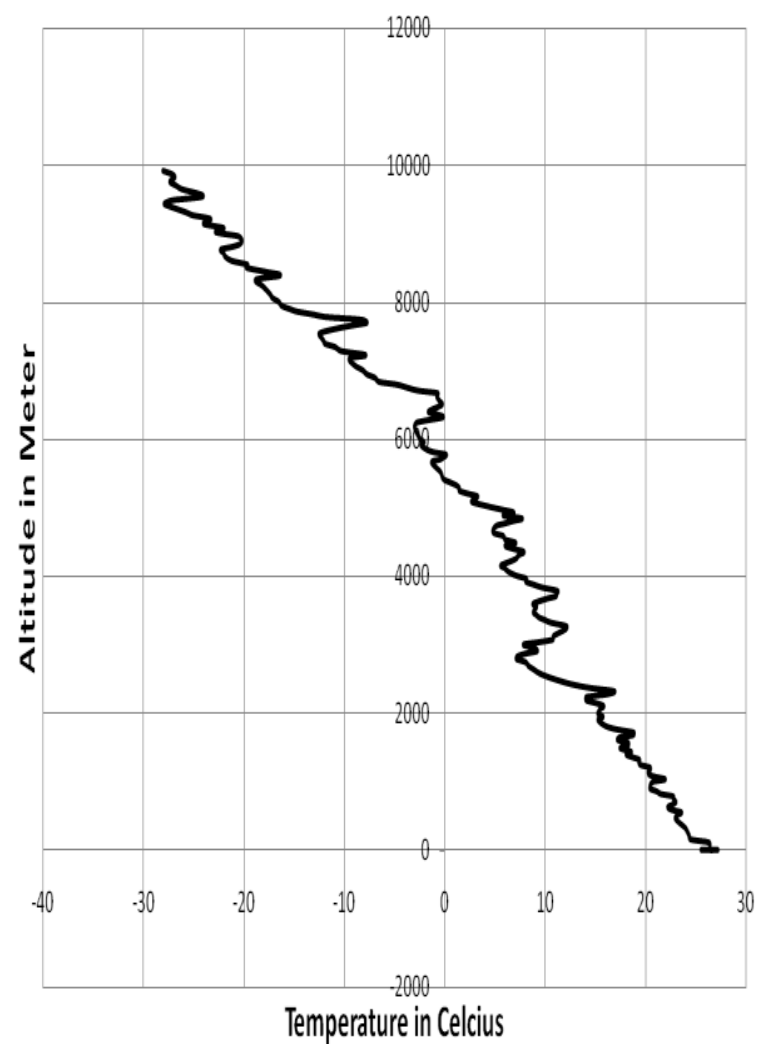

Fig. 10. Temperature Record During Payload Ascending

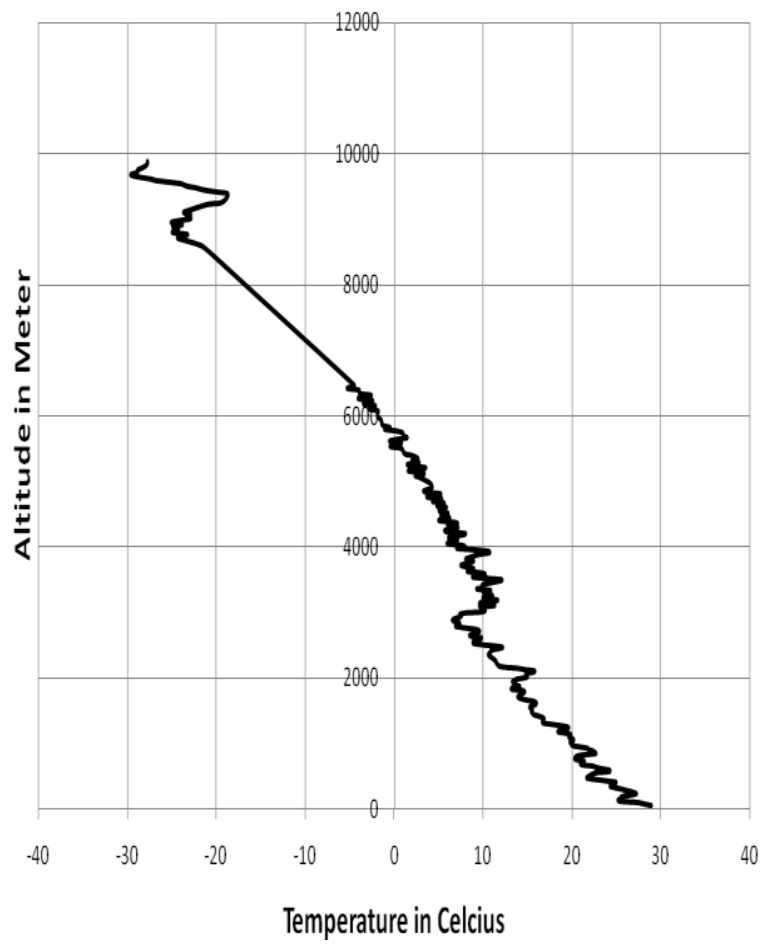

Fig. 11. Temperature Record During Payload Descending 


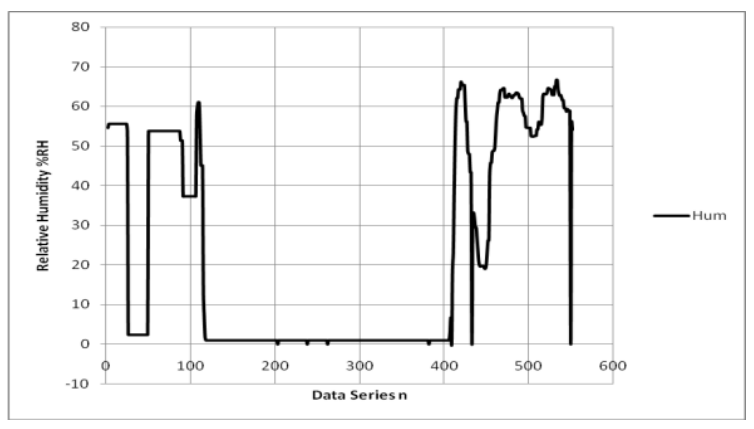

Fig. 12. Temperature Record During Payload Descending

Figure 12 show relative humidity data during mission. Humidity sensor seem not work properly because gives false value during mission.

GS also receive some image that capturing and sending by payload. Figure 13 shows that picture.
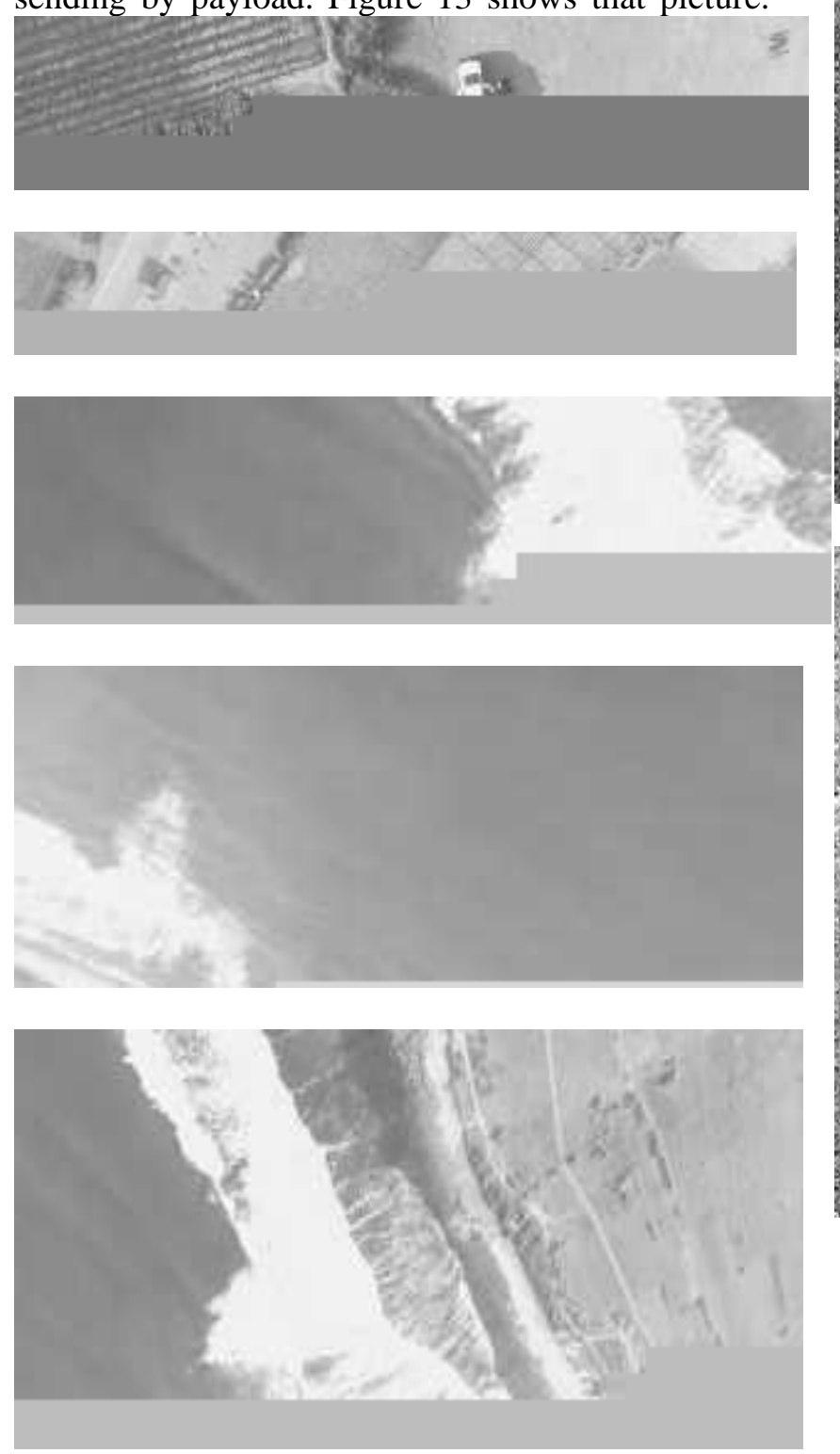

Fig. 13. Received Image
In figure 13 show received image from payload during mission. Only few picture can read and provide some information. Most of the picture received by GS become unreadeble. Some readeble picture show many noise that indicate transmission suffer from interference. Figure 14 shows snap image from video transmission. Althought GS can receive video from payload, video quality is poor and shown many noise. This occured because video transmission still in analog mode. Both image in figure 14 still produce good information, sea surface and costal area still visible. Figure 15 shows high altitude baloon provided by LAPAN.
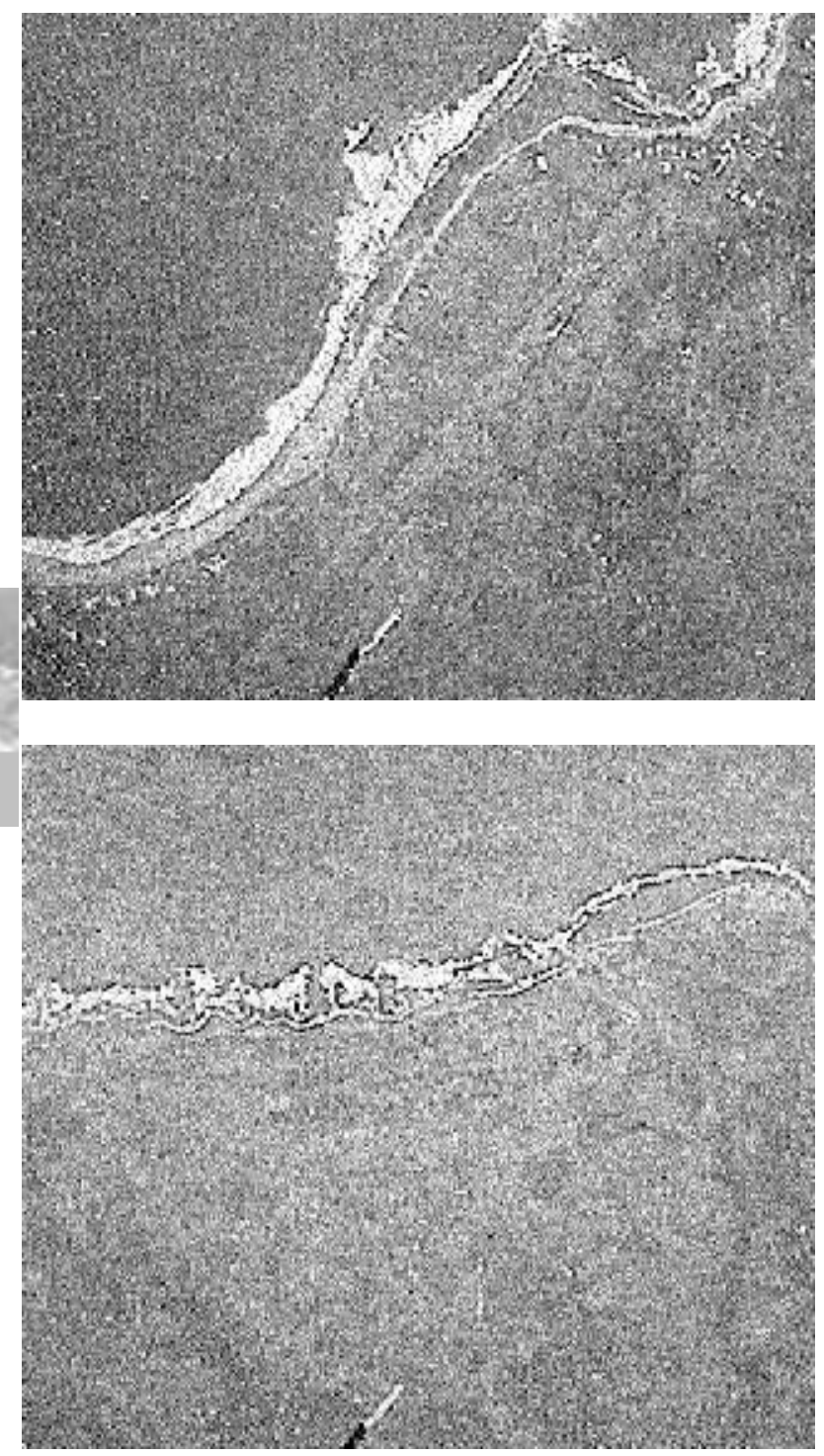

Fig. 14. Snapshot from Video Transmission 


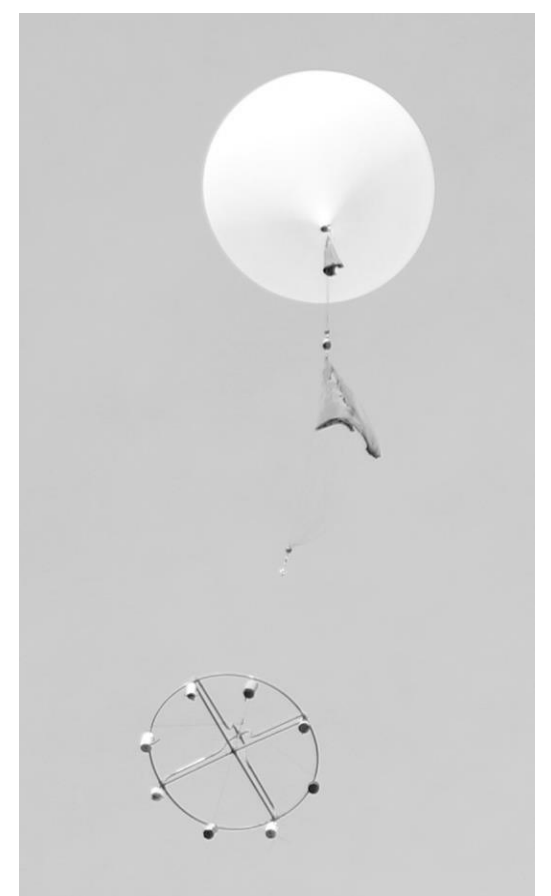

Fig. 15. High Altitude Balloon with Payload

\section{Conclusion}

High altitude ballon payload designed by Microcontroller Research Group Dept.of Electrical Engineering UMY can work well during competition. Atmospheric data such as air pressure and temperature with altitude can recorded from ground station. This data show result that sensor used in payload very reliable. Real time video image transmission can work and gives good early result. Most of critical component like microcontroller and Raspberry $\mathrm{Pi} \mathrm{A}+$ survive during mission in extreme environment . Humidity sensor seem not work properly because gives false value during mission.

Further research needs to be done to perfect the payload and ground station design. Payload can load more variative sensor so that measure more atmospheric parameter. Improvement in algorithm, especially in sending image using low bitrate can also improve result.

\section{Acknowledgements}

This work was supported by Universitas Muhammadiyah Yogyakarta. Indonesian National Institute of Aeronautics and Space (LAPAN) with Ministry of Research, Technology and Higher Education (Ristekdikti) as KOMBAT organizer.

\section{References}

[1] Measurement Specialties Inc. (2013). HTU21D(F) Relative Humidity sensor with Temperature output Datasheet, (October), 1-21.

[2] 3D Robotics Inc. (2013). 3DR Radio V2. Retrieved from https://3dr.com/wpcontent/uploads/2016/02/3DR-Radio-V2-doc1.pdf

[3] Measurement Specialties Inc. MS5611-01BA03 Barometric Pressure Sensor Datasheet. (2012), (1), $1-20$.

[4] Waydo, S., Henry, D., \& Campbell, M. (2002). CubeSat design for LEO-based Earth science missions. IEEE Aerospace Conference Proceedings, $1, \quad 435-445$. http://doi.org/10.1109/AERO.2002.1036863

[5] Kimm, H., Kang, J. S., Bruinga, B., \& Ham, H. S. (2015). Real Time Data Communication Using High Altitude Balloon Based on Cubesat Payload. Journal of Advances in Computer Networks, 3(3), 186-190. http://doi.org/10.7763/JACN.2015.V3.164

[6] Sobester, A., Johnston, S., Scanlan, J., O’Brien, N., Hart, E., Crispin, C., \& Cox, S. (2011). High Altitude Unmanned Air System for Atmospheric Science Missions. In 11th AIAA Aviation Technology, Integration, and Operations (ATIO) Conference. American Institute of Aeronautics and Astronautics. http://doi.org/doi:10.2514/6.2011-6957

[7] Strong, K. (2006). Probing the Atmosphere from Balloon Platforms. Atmospheric Environment, (416), $1-8$.

[8] Nakaya, K. and K. K. and S. H. and U. K. and O. H. and M. N. and I. M. and U. T. and Y. N. and K. M. and O. K. and M. I. and M. S. and T. R. (2003). Tokyo Tech CubeSat: CUTE-I. 21st International Communications Satellite Systems Conference and Exhibit AIAA, 1-10.

[9] Larsen, M. F. (2003). OBSERVATION PLATFORMS | Rockets, 1449-1454. http://doi.org/http://dx.doi.org/10.1016/B0-12227090-8/00258-X

\section{Authors' information}

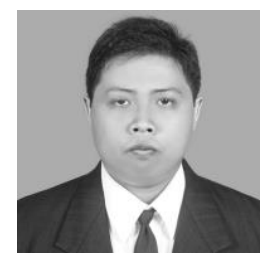

Rama Okta Wiyagi Received B.Sc degree from Department of Electrical Engineering Universitas Muhammadiyah Yogyakarta in 2009, M.Eng. degree from Department of Electrical Engineering and Informatics Technology, Universitas Gadjah Mada, Yogyakarta, Indonesia in 
2014. Rama Okta Wiyagi, M.Eng. is a Lecturer in Department of Electrical Engineering, Faculty of Engineering, Universitas Muhammadiyah Yogyakarta, Indonesia. His research interests are in robotics, robotics vision and instrumentation.

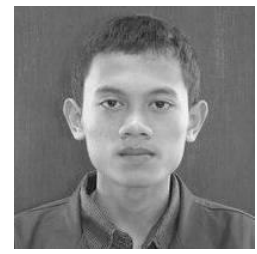

Danardono was senior student in Department of Electrical Engineering Universitas Muhammadiyah Yogyakarta at the time of this projects. His research interest are in instrumentation software engineering and electrical power.

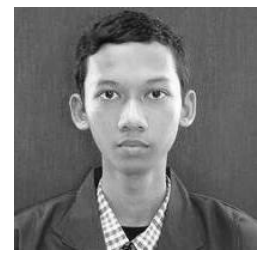

Try Ahmad Agus was senior student in Department of Electrical Engineering Universitas Muhammadiyah Yogyakarta at the time of this projects. His research interest are in microcontroller, robotics and software development under Linux. 